\title{
Outcome of community- versus hospital- acquired intra-abdominal infections in intensive care unit: a retrospective study
}

Timothée Abaziou ${ }^{1 *}$ (D) Fanny Vardon-Bounes ${ }^{1}$, Jean-Marie Conil ${ }^{1}$, Antoine Rouget ${ }^{1}$, Stéphanie Ruiz ${ }^{1}$, Marion Grare², Olivier Fourcade ${ }^{1}$, Bertrand Suc ${ }^{3}$, Marc Leone ${ }^{4}$, Vincent Minville ${ }^{1}$ and Bernard Georges ${ }^{1}$

\begin{abstract}
Background: To compare patients hospitalised in the intensive care unit (ICU) after surgery for communityacquired intra-abdominal infection (CA-IAI) and hospital-acquired intra-abdominal infection (HA-IAl) in terms of mortality, severity and complications.

Methods: Retrospective study including all patients admitted to 2 ICUs within $48 \mathrm{~h}$ of undergoing surgery for peritonitis.

Results: Two hundred twenty-six patients were enrolled during the study period. Patients with CA-IAI had an increased 28-day mortality rate compared to those with HA-IAI (30\% vs $15 \%$, respectively $(p=0.009)$ ). At 90 days, the mortality rates were 36.7 and $37.5 \%$ in the CA-IAI group and HA-IAI group, respectively, with a similar APACHE II score on admission (median: 21 [15-25] vs. 21 [15-24] respectively, $p=0.63$ ). The patients with HA-IAI had prolonged ICU and hospital stays (median: 17 [7-36] vs. 6[3-12] days, $p<0.001$ and 41 [24-66] vs. 17 [7-32] days, $p=0.001$ ), and experienced more complications (reoperation and reintubation) than those with CA-IAI.
\end{abstract}

Conclusion: CA-IAI group had higher 28-day mortality rate than HA-IAI group. Mortality was similar at 90 days but those with HA-IAI had a prolonged ICU and hospital stay. In addition, they developed more complications.

Keywords: Intra-abdominal infection, Peritonitis, Outcome, Microbiology, Intensive care unit

\section{Background}

In some studies, the mortality of patients developing severe intra-abdominal infection (IAI) reaches 50\% [1-3]. Among severe intra-abdominal infections, peritonitis is classified according to one of 3 categories: primary, with a medical aetiology and treatment; secondary, of surgical origin representing the most prevalent cases; and tertiary, with an ongoing intra-abdominal infection despite appropriate care [2] . In the case of secondary peritonitis,

\footnotetext{
* Correspondence: TAbaziou@chu-grenoble.fr

'Département D'Anesthésie-Réanimation (Department of Anesthesia and ICU), CHU Rangueil (University Hospital Centre of Rangeuil), 1 Avenue du Professeur Jean Poulhes TSA 50032, 31059 Toulouse, France

Full list of author information is available at the end of the article
}

treatment is surgical, requiring peritoneal washing after bacteriological sampling, and repair of gut lesions, associated with antibiotics and support for organ failure [2, 4]. Two types of IAI are defined: community-acquired IAI (CA-IAI) and hospital-acquired (HA-IAI) [3].

CA-IAI has a florid presentation, with fever and peritoneal signs. Escherichia coli (E. coli) is the most frequently found bacteria [5-7].

In contrast, peritoneal signs are less apparent in patients with HA-IAI. Although E. coli is still the most frequent bacteria, antimicrobial resistance is commonplace. Pseudomonas aeruginosa, extended spectrum beta lactamase Enterobacteriae or methicillin-resistant

(c) The Author(s). 2020 Open Access This article is licensed under a Creative Commons Attribution 4.0 International License, which permits use, sharing, adaptation, distribution and reproduction in any medium or format, as long as you give appropriate credit to the original author(s) and the source, provide a link to the Creative Commons licence, and indicate if changes were made. The images or other third party material in this article are included in the article's Creative Commons licence, unless indicated otherwise in a credit line to the material. If material is not included in the article's Creative Commons licence and your intended use is not permitted by statutory regulation or exceeds the permitted use, you will need to obtain permission directly from the copyright holder. To view a copy of this licence, visit http://creativecommons.org/licenses/by/4.0/ The Creative Commons Public Domain Dedication waiver (http://creativecommons.org/publicdomain/zero/1.0/) applies to the data made available in this article, unless otherwise stated in a credit line to the data. 
Staphylococcus aureus are also involved, depending on the local ecology [5, 8-10].

The aim of this study was to compare the 28-day mortality rate between patients admitted to ICU with CA-IAI and HA-IAI. Secondary objectives are to describe mortality-related factors, complications, length of stay, microbiological findings and antibiotic treatment.

\section{Methods}

This was a retrospective study enrolling ICU patients from two university hospitals from January 2009 to May 2013, treated for secondary or tertiary peritonitis. The local ethics committee (Comité d'Ethique de la Recherche de Toulouse) approved this study (No. 611112). According to French legislation, patient consent was waived.

The patients treated for secondary IAI with no surgical treatment (radiological puncture or withdrawal of care), or patients transferred to ICU $48 \mathrm{~h}$ after surgical procedure were not included. The patients were treated according to local and international guidelines $[2,4]$.

\section{Definitions}

We defined two groups of patients, CA-IAI group and HA-IAI group, according to national and international guidelines $[11,12]$. The HA-IAI group comprised patients with postoperative IAI and IAI diagnosed at least $48 \mathrm{~h}$ after hospitalisation, regardless of the reason for admission. Patients were classified in the CA-IAI group if they didn't meet HA IAI definition. The attending physician diagnosed postoperative IAI, but we included only patients requiring a surgical procedure.

\section{Surgical management}

All included patients underwent surgery and required laparotomy. Laparotomy was decided by the attending surgeon, and justified by severity of the infection and/or because it was a postoperative IAI. The attending surgeon confirmed the intra-abdominal infection, performed peritoneal lavage with isotonic sodium chloride solution after peritoneal sample. Surgical repair and/or resection were achieved as the attending surgeon decided, and ostomies were preferred at primary anastomosis. Temporary abdominal closure with negative pressure was not routinely used and left at the attending surgeon's discretion. Patients were reoperate on-demand in most cases, except for patients with mesenteric ischemia who were reoperate $48 \mathrm{~h}$ after the initial surgery.

\section{Data collected}

We recorded baseline demographic data [age, gender, body mass index (BMI)], medical history, the use of antibiotic treatment in the 28 days prior to surgery, lesion site, the type of IAI (localised or generalised), the Mannheim Peritonitis Index and the APACHE II score on admission to the ICU $[13,14]$. During the first $24 \mathrm{~h}$ after surgery, we recorded the need for mechanical ventilation for more than $24 \mathrm{~h}$, the need for norepinephrine infusion, plasma creatinine concentrations above $150 \mu \mathrm{mol} /$ L, prothrombin times below $50 \%$ and platelet counts of less than $50,000 / \mathrm{mm}^{3}$. In the $48 \mathrm{~h}$ after surgery, the need for renal replacement therapy was also documented.

Peritoneal sample cultures with the antibiotic susceptibility test, the empirical antibiotic treatment chosen and suitability in relation to the bacterial results obtained were recorded. Microbiological procedures were those routinely used in the local laboratory, according to the French Society of Microbiology [15].

We assessed the appropriateness of the empirical antimicrobial therapy, defined by at least one antimicrobial active against the pathogens that were identified by the microbiological cultures. We defined empiric antibiotic treatment as antibiotic given before bacteriological results, and directed as directed by antibiotic susceptibility.

The hospital and ICU length of stay from hospital admission (ward or ICU), 28-day and 90-day mortality rate after surgery, 28 ventilator-free days and 28 antibioticfree days over the postoperative period, re-intubation, limitation or withdrawal of care and revision surgery were also documented.

\section{Statistical analysis}

Statistical analyses were performed with $\mathrm{R}$ software ( $\mathrm{R}$ Core Team (2014). R: A language and environment for statistical computing. R Foundation for Statistical Computing, Vienna, Austria. URL http://www.R-project.org/). Student's t test or Mann-Whitney's test were used to compare quantitative variables as appropriate, and Chi2 test or Fisher test to compare binomial variables, as required. Data was expressed as median values with 1 st and 3rd interquartile or percentage. We used KaplanMeier curves to represent changes in the mortality rate in the first 28 days post-admission. We carried out Cox model regression in order to establish mortality-related factors. We included significant variables in the univariate analysis when this variable was present on or before admission. We chose the model with the higher concordance index. Before modelling, we used multiple imputations to deal with missing data. Categorical variables are expressed as number (\%). Quantitative variables are expressed as median [1st - 3rd quartile]. A two-sided $p$ value of less than 0.05 was considered to be statistically significant.

\section{Results}

During the study period, 304 cases were screened, 78 were excluded and 226 were enrolled - 90 in the CA-IAI 
group and 136 in the HA-IAI group (Fig. 1). Demographic characteristics are summarised in Table 1 . The 2 groups had similar baseline characteristics except for prior antibiotics administration in the 28 days before surgery $(16 \%$ in the CA-IAI group vs. $52 \%$ in the HAIAI group, $p<0.001)$ and aetiology.

\section{8-day mortality rate and mortality-related factors}

The 28-day mortality rate was 30 and $15 \%$ in the CAIAI group and the HA-IAI group, respectively $(p=$ $0.009)$. The Kaplan-Meier curve analysis confirmed this difference $(p=0.001)$ (Fig. 2). Using a Cox model, CAIAI (hazard ratio (HR): 3.0 [1.7-5.5], $p<0.001$ ), peripheral vascular disease history (HR: 2.10 [1.07-3.99], $p=$ 0.031), platelet count below 50,000 $/ \mathrm{mm}^{3}$ (HR: 1.9 [1.01-3.73], $\quad p=0.047)$, plasma creatinine above $150 \mu \mathrm{mol} / \mathrm{L}$ (HR: 3.00 [1.43-6.13], $p=0.003$ ) were associated with the 28-day mortality rate, and BMI above 23 (HR: 0.91 [0.86-0.97], $p=0.003$ ) was associated with a lower rate (Fig. 3). The concordance index was 0.77 . The likelihood ratio test, the Wald test and the logrank test were significant $(p<0.001)$.

\section{Other outcomes}

Compared to the CA-IAI group, the HA-IAI group had a prolonged ICU and hospital stay (17 [7-36] vs. 6 [312] days, $p<0.001$ and 41 [24-66] vs. 17 [7-32 days, $p<$ 0.001 , respectively) (Table 2 ). This group required more repeat operations ( $21 \%$ vs. $9 \%$ ) and re-intubation $(41 \%$ vs. $17 \%)$. A decision to withdraw care was taken for $18 \%$ of patients in the CA-IAI group and 19\% of patients in the HA-IAI group $(p=0.85)$. The 90 -day mortality rate was similar in both groups (35.6 vs. 31.6 for CA-IAI group and HA-IAI group, respectively, $p=0.54$ ). On day 28 , the number of mechanical ventilation-free days was 20 [0-27] and 11 [0-23] days in the CA-IAI group and the HA-IAI group, respectively $(p=0.039)$. Similarly, the number of antibiotic-free days was 13 [0-18] and 5 [013 days in the CA-IAI group and the HA-IAI group, respectively $(p=0.024)$.

\section{Bacteriological findings and antibiotic treatment}

In our study, peritoneal samples were collected from 49 (54\%) patients in the CA-IAI group and 119 (88\%) patients in the HA-IAI group (Table 3), resulting in 102 and 257 isolates in the CA-IAI and HA-IAI groups, respectively. In both groups, E. coli was the main bacteria identified, and Enterococcus faecalis was the main Grampositive cocci found.

In both group, Candida albicans was the main yeast identified, 10 cases in CA-IAI group vs. 25 in the HAIAI $(p=0.85)$. Other species were found in 8 cases in the CA-IAI group (3 C. parapsilosis, 1 C. inconspicua, 1 C. norengensis, 1 Saccharomyces cerevisae, 1 Sporopachydermia lactativora and 1 unidentified yeast), and in 18 cases in the HA-IAI group (6 C. glabrata, 4 C. krusei, 2 C. tropicalis, 1 C. kefir, 1 C. fumata, 1 C. inconspicua, 1 Aspergillus fumigatus, 1 Saccharomyces cerevisae, and 1 unidentified yeast). For patients with positive peritoneal samples (46 samples in CA-IAI group, 111 in the HAIAI group), the antibiotic treatment was adequate for 38 patients in the CA-IAI group (78\%) and for 93 patients in the HA-IAI group $(84 \%)(p=0.4)$. Inappropriate antibiotic treatment was due to the presence of E. faecium

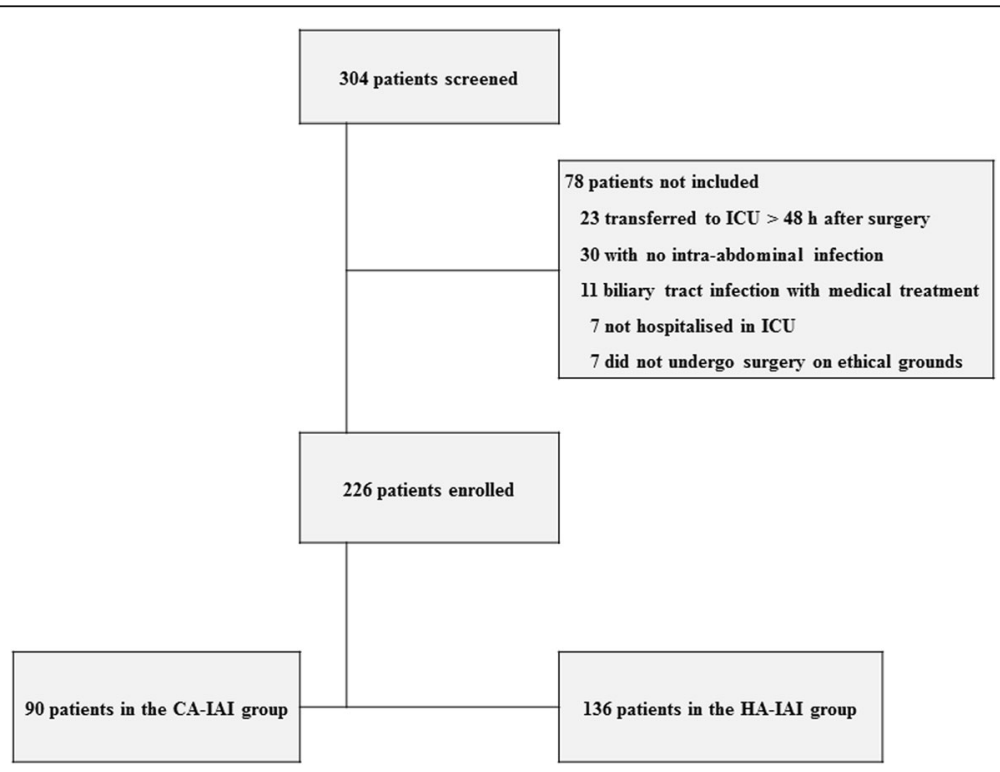

Fig. 1 Flow chart of enrolment. CA-IAI: community-acquired Intraabdominal Infection; HA-IAI: hospital-acquired Intraabdominal Infection 
Table 1 Demographic characteristics of the study population

\begin{tabular}{|c|c|c|c|c|c|}
\hline \multirow{3}{*}{ Male, n (\%) } & \multirow{2}{*}{\multicolumn{2}{|c|}{$\begin{array}{l}\text { CA-IAI } \\
(n=90)\end{array}$}} & \multirow{2}{*}{\multicolumn{2}{|c|}{$\frac{\text { HA-IAI }}{(n=136)}$}} & \multirow{3}{*}{$\begin{array}{l}p \\
0.48\end{array}$} \\
\hline & & & & & \\
\hline & 52 & $(57.8)$ & 85 & $(62.5)$ & \\
\hline Age, years median [IQR] & 66 & {$[52-78]$} & 67 & {$[57-76]$} & 0.86 \\
\hline BMI median [IQR] & 24 & [22-30] & 25 & [22-28] & 0.84 \\
\hline \multicolumn{6}{|l|}{ Medical history, n (\%) } \\
\hline coronary disease & 25 & $(27.8)$ & 29 & $(21.3)$ & 0.26 \\
\hline arterial occlusive disease & 16 & $(17.8)$ & 17 & $(12.5)$ & 0.36 \\
\hline cardiac insufficiency & 5 & (5.6) & 6 & $(4.4)$ & 0.26 \\
\hline chronic renal failure & 5 & $(5.6)$ & 11 & $(8.1)$ & 0.64 \\
\hline chronic dialysis & 1 & $(1.1)$ & 1 & $(0.7)$ & 1 \\
\hline cirrhosis & 4 & $(4.4)$ & 6 & $(4.4)$ & 1 \\
\hline diabetes mellitus & 16 & $(17.8)$ & 19 & $(13.9)$ & 0.44 \\
\hline immunodeficiency & 16 & $(17.8)$ & 23 & $(16.9)$ & 0.86 \\
\hline abdominal surgery & 39 & $(43.3)$ & 64 & $(47.1)$ & 0.58 \\
\hline Prior antibiotic treatment, $\mathrm{n}(\%)$ & 14 & $(15.6)$ & 70 & $(51.5)$ & $<0.001$ \\
\hline Generalised peritonitis, n (\%) & 28 & $(31.1)$ & 56 & $(41.2)$ & 0.62 \\
\hline \multicolumn{5}{|l|}{ Localisation, n (\%) } & 0.36 \\
\hline colon & 38 & $(42.2)$ & 61 & $(44.9)$ & \\
\hline small intestine & 28 & $(31.1)$ & 28 & $(20.6)$ & \\
\hline stomach/duodenum & 15 & $(16.7)$ & 20 & $(14.7)$ & \\
\hline other & 9 & (10) & 25 & $(18.4)$ & \\
\hline \multicolumn{5}{|l|}{ Aetiology } & $<0.001$ \\
\hline Perforation & 59 & $(65.6)$ & 34 & $(24.5)$ & \\
\hline Ischaemia & 20 & $(22.2)$ & 19 & $(13.7)$ & \\
\hline Anastomotic leakage & 0 & (0) & 35 & $(25.2)$ & \\
\hline Po with no lesion found & 0 & (0) & 28 & $(20.6)$ & \\
\hline Po abscess & 0 & (0) & 6 & $(4.3)$ & \\
\hline Trauma & 8 & $(8.9)$ & 5 & (3.6) & \\
\hline Other & 3 & $(3.4)$ & 9 & $(6.5)$ & \\
\hline APACHE ॥ & 21 & [15-25] & 21 & [15-24] & 0.63 \\
\hline MPI & 23 & [16-28] & 24 & [17-28] & 0.24 \\
\hline Mechanical ventilation > 24 h, n (\%) & 61 & $(67.8)$ & 107 & $(78.7)$ & 0.052 \\
\hline Norepinephrine, n (\%) & 63 & $(70.0)$ & 106 & $(78.0)$ & 0.12 \\
\hline Plasma creatinine level > $150 \mu \mathrm{mol} / \mathrm{L}, \mathrm{n}(\%)$ & 41 & $(45.6)$ & 63 & $(46.3)$ & 0.89 \\
\hline PT < 50\%, n (\%) & 23 & $(25.6)$ & 38 & $(28.0)$ & 0.66 \\
\hline Platelet $<50,000 / \mathrm{mm}^{3}, \mathrm{n}(\%)$ & 16 & $(17.8)$ & 15 & $(11.0)$ & 0.16 \\
\hline Renal replacement therapy, n (\%) & 25 & $(27.8)$ & 50 & (36.8) & 0.15 \\
\hline
\end{tabular}

$B M I$ Body mass index. Immunodeficiency was defined by haematological cancer, active solid cancer, AIDS Immunosuppressive therapy and corticosteroid therapy initiated at least 1 month before. MV > $24 \mathrm{~h}$ : Mechanical ventilation still ongoing $24 \mathrm{~h}$ after admission. PT Prothrombin time. APACHE I/ APACHE II score on admission after surgical management. MPI Mannheim Peritonitis Index. Po: postoperative

(3 vs. 10 patients in the CA-IAI and HA-IAI groups, respectively). The antibiotic treatment was subsequently adjusted according to antibiotic susceptibility in $73 \%$ of patients in the CA-IAI group and $82 \%$ in the HA-IAI group $(p=0.15)$. A combination of piperacillin/ tazobactam and amikacin was the most widely prescribed antibiotic in the 2 groups (43 and $63 \%$ in the CA-IAI and HA-IAI groups, respectively, $p=0.003$ ). An antifungal treatment was administered concomitantly for 40 patients in the CA-IAI group (44\%, caspofungin in 21 

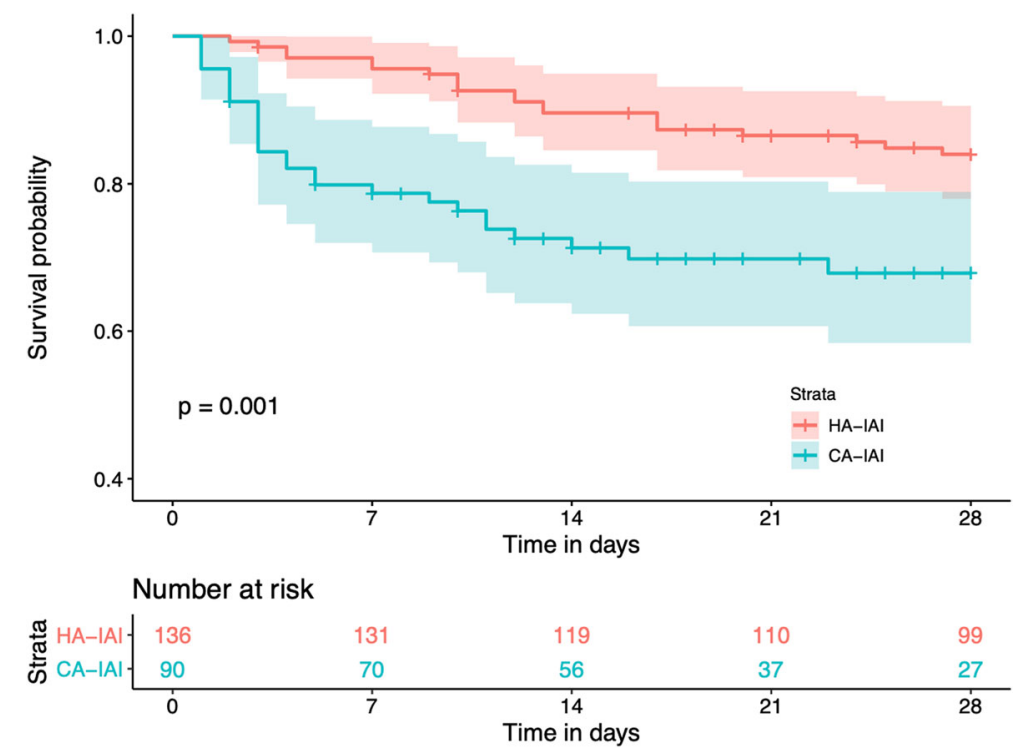

Fig. 2 Kaplan-Meier curve of survival rate at 28 days, with 95\% confidence interval. Blue line: CA-IAl: community-acquired Intraabdominal Infection; Red line: HA-IAl: hospital-acquired Intraabdominal Infection

cases, fluconazole in 19 cases) and 78 patients in the HA-IAI group (57\%, caspofungin in 49 cases, fluconazole in 30 , and voriconazole in 1 case) $(p=0.057)$.

\section{Discussion}

In our study, CA-IAI patients had a higher 28-day mortality rate than those with HA-IAI. However, at 90 days, the mortality rates were similar in both groups. Based on our knowledge, few studies actually compare outcomes for patients with CA-IAI and HA-IAI. Van Ruler et al. noted mortality rates of $13 \%$ for patients with CA-IAI and $30 \%$ for those with HA-IAI, including patients with an APACHE II score above 10 [7]. Montravers et al. found a mortality rate of $4 \%$ for patients with CA-IAI and $12 \%$ for patients with hospital-acquired, nonpostoperative peritonitis in a mixed population of ICU and non-ICU patients [16]. Inui et al. observed a mortality rate of $3.8 \%$ for patients with CA-IAI and $8.4 \%$ for HA-IAI patients. This study included IAI with or without surgical treatment [17]. In a multicentre study, no significant difference in mortality rate was reported in patients with CA-IAI and HA-IAI [5]. These findings probably reflect differences in the inclusion criteria, endpoint definitions and the type of IAI.

We can only assume the reason for the difference in the 28-day mortality rate. Our two groups are similar in terms of severity criteria and APACHE II score. However, delay between the onset of symptoms, initiation of antibiotic treatment and surgical management could not be reliably collected, which can be a major confounding bias. Time between clinical onset and antibiotics or operating room for patients in CA-IAI group could have

\begin{tabular}{|c|c|c|c|c|c|c|}
\hline \multicolumn{7}{|c|}{ Hazard ratio } \\
\hline & $C A-|A|$ & $(N=226)$ & $\begin{array}{l}3.2 \\
(1.76-5.77)\end{array}$ & $\rightarrow$ & $<0.001 *$ & $\ldots$ \\
\hline & arterial occlusive disease & $(N=226)$ & $\left(1.20^{2.3}-4.33\right)$ & $\longmapsto$ & $0.012^{*}$ & \\
\hline & BMI & $(N=226)$ & $(0.85-0.96) \quad H$ & & $<0.001 *$ & \\
\hline & Creatinine $>150$ & $(N=226)$ & $(1.97-7.54)$ & 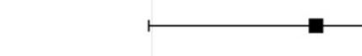 & $\longrightarrow<0.001 *$ & \\
\hline & platelet $<50000$ & $(N=226)$ & $\left(1.19^{2.3}-4.27\right)$ & $\longmapsto$ & $0.013^{*}$ & \\
\hline & $\begin{array}{l}\text { \# Events: 48; Global } p \text {-value } \\
\text { AIC: } 463.22 ; \text { Concordance It }\end{array}$ & $\begin{array}{l}\text { e (Log-Rank } \\
\text { Index: } N A\end{array}$ & & 2 & 10 & \\
\hline
\end{tabular}


Table 2 Length of stay and complications

\begin{tabular}{llll}
\hline & $\begin{array}{l}\text { CA-IAI } \\
(\boldsymbol{n}=\mathbf{9 0})\end{array}$ & $\begin{array}{l}\text { HA-IAI } \\
(\boldsymbol{n}=\mathbf{1 3 6})\end{array}$ & $\boldsymbol{p}$ \\
\hline ICU LOS, median [IQR] & $6[3-12]$ & $17[7-36]$ & $<0.001$ \\
Hospital LOS, median [IQR] & $17[7-32]$ & $41[24-66]$ & $<0.001$ \\
Reoperation, n (\%) & $8(9.0)$ & $28(20.7)$ & 0.019 \\
Reintubation, n (\%) & $17(19.5)$ & $54(40.6)$ & $<0.001$ \\
Withdrawal of care, n (\%) & $16(18.4)$ & $26(19.4)$ & 0.85 \\
Death at 90 days, n (\%) & $32(35.6)$ & $43(31.6)$ & 0.54 \\
\hline
\end{tabular}

ICU Intensive care unit; LOS Length of stay; IQR Interquartile range

been more important than recommended, which could explain the increased mortality rate. No peritoneal sample was collected for a large number of CA-IAI patients. Therefore, we did not know whether antimicrobial treatment was adequate for these patients. Furthermore, inpatients were more likely to receive broad-spectrum

Table 3 Main bacteriological findings in CA-IAI (46 patients) and HA-IAl groups (111 patients)

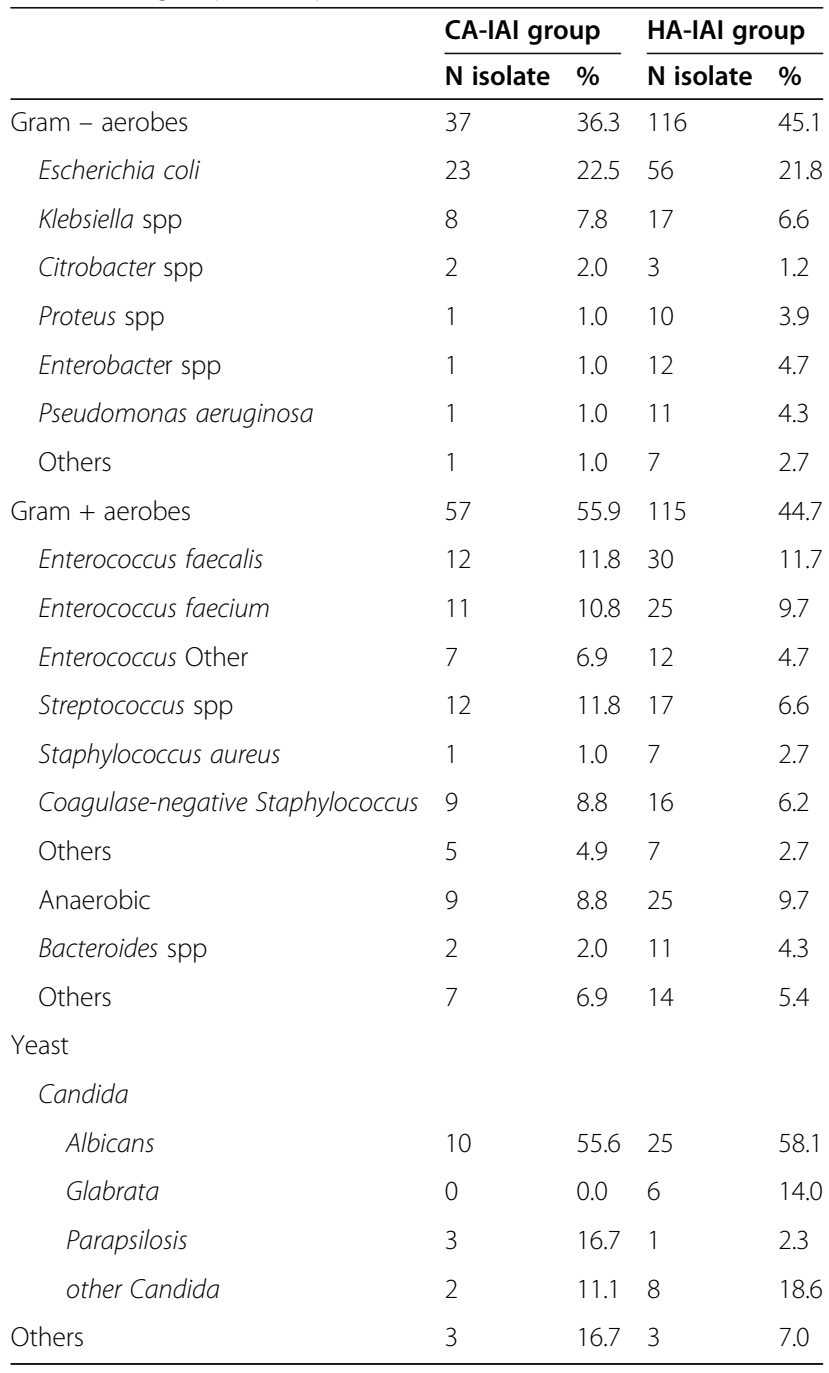

antibiotics. Some patients from the HA-IAI group were already in the ICU when peritonitis developed, and therefore returned to the ICU after surgical management regardless of the severity criteria. These differences could explain why death occurred earlier in the CA-IAI group than in the HA-IAI group. However, it should be noted that the mortality rate was similar at 90 days.

It is important to notice that the 2 ICUs from where patients were included take care of the most severe cases hospitalized in our institution. Less severe cases, with only one organ failure and not mechanically ventilated are usually hospitalized in other intensive care units.

A medical history of arterial occlusive disease, platelet count below 50,000/mm3, creatinine serum levels greater than $150 \mu \mathrm{mol} / \mathrm{l}$, and a high APACHE II score were also associated with a worse outcome. A BMI of over 23 was associated with a better outcome. Thrombocytopenia had already been described as a mortality-related factor in IAI, and acute kidney injury in critically ill patients and sepsis in particular $[18,19]$. A meta-analysis studying overweight, obesity and sepsis reported an association with a better outcome [20]. To the best of our knowledge, arterial occlusive disease has not been previously described as a mortality-related factor, but its association with coronary disease is well known, which could explain our findings [21].

Other outcomes, as defined by our study, have generally been poorly reported in previous studies, except for reoperation. This last endpoint is generally higher in HA-IAI patients $[9,17]$. As in other studies, we report longer ICU and hospital stays for HA-IAI patients compared to those with CA-IAI [17, 22].

The bacteriological findings were consistent with the literature, except for the rate of anaerobic bacteria [5, 23]. This may be attributed to poor quality of sampling, conditioning or logistics of the peritoneal sample. Our institution has taken measures to improve this. Empirical antibiotic therapy was appropriate in $72.5 \%$ of the CAIAI group and $82.2 \%$ of the HA-IAI group. The presence of amoxicillin-resistant Enterococcus faecium was the main reason for inappropriate antibiotic therapy, as confirmed in earlier findings [5, 24, 25]. A combination of piperacillin/tazobactam with amikacin was the most widely prescribed empirical antibiotic therapy. It was administered to approximately $50 \%$ of patients. For CAIAI patients, this treatment is in accordance with French and International guidelines, although the benefit of aminoglycosides is not proven in this indication $[2,4$, 26, 27]. As regards HA-IAI patients, carbapenems are currently proposed in guidelines when specific conditions are found $[2,4]$. Otherwise, piperacillin/tazobactam is indicated, possibly in conjunction with an aminoglycoside and/or vancomycin. Inadequate empirical antibiotic treatment is associated with poor prognosis, increased 
morbidity and mortality rates, reoperation and prolonged ICU or hospital stays [22, 28-30].

Our study has several limitations. Firstly, this is a retrospective study with missing data. Especially as already mentioned, time between diagnosis, antibiotics and surgery were not consistently or reliably recorded. These parameters are known to have a major impact on patients' outcome, and the lack of these data might affect our results. Antibiotic treatment duration for IAI was not always explicitly reported, and knowing when the course stopped and a new one for other infection begin was not always possible, explaining why we used 28 -antibiotics free days. If focus control of the infection was possible after surgery was also not clearly reported, but we did not found any evidence to the contrary. Secondly, the patients were included from two hospitals only, making it difficult to extrapolate our findings. Thirdly, not all patients had a peritoneal sample prior to surgery, particularly in the CA-IAI group. As mentioned above, the impact of the initial antibiotic on the microbiological findings, which is generally associated with good outcome in terms of mortality rates or complications, was not analysed in our study. This situation had been already reported in another study, and the rate of peritoneal sampling needs to be improved as recommended in current guidelines [24, 31, 32]. Fourthly, recruitment period begun in 2009, and critically ill patients management has evolved since then, which could make extrapolation of our results difficult. And lastly, we did not included patients transferred $48 \mathrm{~h}$ after surgery as we assumed their transfer were not directly related from IAI and septic shock, or if so, would have been done after revision, and were more related to patients' medical history. This might lead to selection bias and less daily practice representability.

\section{Conclusion}

In our study, CA-IAI patients were surprisingly at higher risk of 28-day mortality after ICU admission than those with HA-IAI. The need for reoperation and reintubation increased in the HA-IAI group in conjunction with prolonged ICU and hospital stays. However, the increased 28-day mortality rate was not confirmed at 90 days. Therefore, long-term outcomes should be assessed.

\section{Abbreviations \\ |Al: Intra-abdominal infection; CA-IAl: Community-acquired intra-abdominal infection; HA-IAI: Hospital-acquired intra-abdominal infection; ICU: Intensive care unit}

\section{Acknowledgments}

We would like to thank all the ICU and surgical team who take care of the included patients.

\section{Authors' contributions}

TA and BG conceived the design of the study; TA collected the data; TA and JMC did the statistical analysis; TA, BG, ML, VM wrote the first draft of the manuscript; All authors (TA, FVB, JMC, AR, SR, MG, OF, BS, ML, VM and BG) read, revised and approved the final manuscript.

Funding

None.

\section{Availability of data and materials}

The datasets used and analysed during the current study are available from the corresponding author on reasonable request.

\section{Ethics approval and consent to participate}

The local ethics committee (Comité d'Ethique de la Recherche de Toulouse) approved this study (No. 61-1112). According to French legislation, patient consent was waived.

\section{Consent for publication}

Not applicable.

\section{Competing interests}

The authors declare that they have no competing interests.

\section{Author details}

'Département D'Anesthésie-Réanimation (Department of Anesthesia and ICU), CHU Rangueil (University Hospital Centre of Rangeuil), 1 Avenue du Professeur Jean Poulhes TSA 50032, 31059 Toulouse, France. 'Laboratoire de Bactériologie et Hygiène (Bacteriology and Hygiene Laboratory), Institut Fédératif de Biologie (Federative Institute of Biology), 330 Avenue de Grande Bretagne, Cedex 9, 31059 Toulouse, France. ${ }^{3}$ Service de Chirurgie Digestive (Department of Gastrointestinal Surgery), CHU Rangueil (University Hospital Centre of Rangueil), 1 Avenue du Professeur Jean Poulhes, 31059 Toulouse, France. ${ }^{4}$ Aix Marseille Université, Assistance Publique Hôpitaux de Marseille (Public Hospitals of Marseille), Service D’Anesthésie-Réanimation (Department of Anaesthesia and ICU), Hôpital Nord, Chemin des Bourrely, 13015 Marseille, France.

Received: 2 June 2020 Accepted: 19 November 2020

Published online: 01 December 2020

\section{References}

1. Wittmann DH. Intraabdominal infections--introduction. World J Surg. 1990; 14:145-7.

2. Solomkin JS, Mazuski JE, Bradley JS, Rodvold KA, Goldstein EJC, Baron EJ, et al. Diagnosis and Management of Complicated Intra-abdominal Infection in adults and children: guidelines by the surgical infection society and the Infectious Diseases Society of America. Clin Infect Dis. 2010;50:133-64.

3. Sartelli M, Viale P, Koike K, Pea F, Tumietto F, Van Goor H, et al. WSES consensus conference: guidelines for first-line management of intraabdominal infections. World J Emerg Surg. 2011;6:2.

4. SFAR. Prise en Charge des Péritonites Communautaires, Conference de Consensus. 2000. http://reaannecy.free.fr/Documents/consensus/peritonites. pdf. Accessed 9 Aug 2020.

5. Montravers P, Lepape A, Dubreuil L, Gauzit R, Pean Y, Benchimol D, et al. Clinical and microbiological profiles of community-acquired and nosocomial intra-abdominal infections: results of the French prospective, observational EBIIA study. J Antimicrob Chemother. 2009:63:785-94.

6. GenOSept Investigators, Tridente A, Clarke GM, Walden A, McKechnie S, Hutton $\mathrm{P}$, et al. Patients with faecal peritonitis admitted to European intensive care units: an epidemiological survey of the GenOSept cohort. Intensive Care Med. 2014:40:202-10.

7. On behalf of the Dutch Peritonitis Study Group, Ruler O, JJS K, Ketel RJ, Boermeester MA. Initial microbial spectrum in severe secondary peritonitis and relevance for treatment. Eur J Clin Microbiol Infect Dis. 2012;31:671-82.

8. Augustin P, Tran-Dinh A, Valin N, Desmard M, Crevecoeur MA, Muller-Serieys $C$, et al. Pseudomonas aeruginosa post-operative peritonitis: clinical features, risk factors, and prognosis. Surg Infect. 2013;14:297-303.

9. Ballus J, Lopez-Delgado JC, Sabater-Riera J, Perez-Fernandez XL, Betbese AJ, Roncal JA. Surgical site infection in critically ill patients with secondary and tertiary peritonitis: epidemiology, microbiology and influence in outcomes. BMC Infect Dis. 2015;15. https://doi.org/10.1186/s12879-015-1050-5.

10. Gauzit R, Péan Y, Barth X, Mistretta F, Lalaude O. Epidemiology, management, and prognosis of secondary non-postoperative peritonitis: a 
French prospective observational multicenter study. Surg Infect. 2009;10: $119-27$.

11. Horan TC, Andrus M, Dudeck MA. CDC/NHSN surveillance definition of health care-associated infection and criteria for specific types of infections in the acute care setting. Am J Infect Control. 2008;36:309-32.

12. Comité technique des infections nosocomiales et des infections liées aux soins. Définition des infections liées aux soins. 2007. https://solidaritessante. gouv.fr/IMG/pdf/rapport_vcourte.pdf. Accessed 9 Aug 2020.

13. Wacha $H$, Linder M, Feldmann U, Wesch G, Gundlach E, Seifensand R. Mannheim peritonitis index - prediction of risk of death from peritonitis: construction of a statistic and validation of an empirically based index. Theor Surg. 1987:169-77.

14. Knaus WA, Draper EA, Wagner DP, Zimmerman JE. APACHE II: a severity of disease classification system. Crit Care Med. 1985;13:818-29.

15. Société française de microbiologie. Référentiel en microbiologie médicale: référentiel en microbiologie médicale. Paris: Société française de microbiologie; 2018.

16. Montravers P, Chalfine A, Gauzit R, Lepape A, Pierre Marmuse J, Vouillot C, et al. Clinical and Therapeutic Features of Nonpostoperative Nosocomial Intra-abdominal Infections. Ann Surg. 2004;239:409-16.

17. Inui T, Haridas M, Claridge JA, Malangoni MA. Mortality for intra-abdominal infection is associated with intrinsic risk factors rather than the source of infection. Surgery. 2009;146:654-62.

18. Wu Q, Ren J, Wang G, Li G, Gu G, Wu X, et al. The incidence, clinical outcomes, and risk factors of thrombocytopenia in intra-abdominal infection patients: a retrospective cohort study. PLoS One. 2016;11: e0147482.

19. Peters E, Antonelli M, Wittebole X, Nanchal R, François B, Sakr Y, et al. A worldwide multicentre evaluation of the influence of deterioration or improvement of acute kidney injury on clinical outcome in critically ill patients with and without sepsis at ICU admission: results from the intensive care over nations audit. Crit Care. 2018;22. https://doi.org/10.1186/ s13054-018-2112-z.

20. Pepper DJ, Sun J, Welsh J, Cui X, Suffredini AF, Eichacker PQ. Increased body mass index and adjusted mortality in ICU patients with sepsis or septic shock: a systematic review and meta-analysis. Crit Care. 2016;20. https://doi. org/10.1186/s13054-016-1360-z.

21. Hooi JD, Kester ADM, Stoffers HEJH, Rinkens PELM, Knottnerus JA, van Ree JW. Asymptomatic peripheral arterial occlusive disease predicted cardiovascular morbidity and mortality in a 7-year follow-up study. J Clin Epidemiol. 2004;57:294-300.

22. Krobot K, Yin D, Zhang Q, Sen S, Altendorf-Hofmann A, Scheele J, et al. Effect of inappropriate initial empiric antibiotic therapy on outcome of patients with community-acquired intra-abdominal infections requiring surgery. Eur J Clin Microbiol Infect Dis. 2004;23. https://doi.org/10.1007/ s10096-004-1199-0.

23. de Ruiter J, Weel J, Manusama E, Kingma WP, van der Voort PHJ. The epidemiology of intra-abdominal Flora in critically ill patients with secondary and tertiary abdominal Sepsis. Infection. 2009;37:522-7.

24. Sotto A. Evaluation of antimicrobial therapy management of 120 consecutive patients with secondary peritonitis. J Antimicrob Chemother. 2002;50:569-76.

25. Seguin P, Fedun Y, Laviolle B, Nesseler N, Donnio P-Y, Malledant Y. Risk factors for multidrug-resistant bacteria in patients with post-operative peritonitis requiring intensive care. J Antimicrob Chemother. 2010;65:342-6.

26. Dupont H, Carbon C, Carlet J. Monotherapy with a broad-spectrum betalactam is as effective as its combination with an aminoglycoside in treatment of severe generalized peritonitis: a multicenter randomized controlled trial. The severe generalized peritonitis study group. Antimicrob Agents Chemother. 2000;44:2028-33.

27. Wong PF, Gilliam AD, Kumar S, Shenfine J, O'Dair GN, Leaper DJ. Antibiotic regimens for secondary peritonitis of gastrointestinal origin in adults. Cochrane Database Syst Rev. 2005;(2):CD004539. https://doi.org/10.1002/ 14651858.CD004539.pub2.

28. Riché FC, Dray X, Laisné M-J, Matéo J, Raskine L, Sanson-Le Pors M-J, et al. Factors associated with septic shock and mortality in generalized peritonitis: comparison between community-acquired and postoperative peritonitis. Crit Care. 2009;13:R99.

29. Cattan P, Yin D, Sarfati E, Lyu R, de Zelicourt M, Fagnani F. Cost of Care for Inpatients with community-acquired intra-abdominal infections. Eur J Clin Microbiol Infect Dis. 2002;21:787-93.
30. Paul M, Shani V, Muchtar E, Kariv G, Robenshtok E, Leibovici L. Systematic review and meta-analysis of the efficacy of appropriate empiric antibiotic therapy for Sepsis. Antimicrob Agents Chemother. 2010;54:4851-63.

31. Mosdell DM, Morris DM, Voltura A, Pitcher DE, Twiest MW, Milne RL, et al. Antibiotic treatment for surgical peritonitis. Ann Surg. 1991;214:543-9.

32. Pacelli F, Doglietto GB, Alfieri S, Piccioni E, Sgadari A, Gui D, et al. Prognosis in intra-abdominal infections. Multivariate analysis on 604 patients. Arch Surg. 1996;131:641-5.

\section{Publisher's Note}

Springer Nature remains neutral with regard to jurisdictional claims in published maps and institutional affiliations.

\section{Ready to submit your research? Choose BMC and benefit from:}

- fast, convenient online submission

- thorough peer review by experienced researchers in your field

- rapid publication on acceptance

- support for research data, including large and complex data types

- gold Open Access which fosters wider collaboration and increased citations

- maximum visibility for your research: over $100 \mathrm{M}$ website views per year

At BMC, research is always in progress.

Learn more biomedcentral.com/submissions 